\title{
Proteinase-Activated Receptor-2 Agonist Activates Anti-Influenza Mechanisms and Modulates IFN $\gamma$-Induced Antiviral Pathways in Human Neutrophils
}

\author{
Micha Feld, ${ }^{1}$ Victoria Shpacovitch, ${ }^{2}$ Christina Ehrhardt, ${ }^{3}$ Michaela Fastrich, \\ Tobias Goerge, ${ }^{4}$ Stephan Ludwig, ${ }^{3}$ and Martin Steinhoff ${ }^{4,5}$ \\ ${ }^{1}$ Department of Dermatology, Heinrich-Heine University, 40225 Düsseldorf, Germany \\ ${ }^{2}$ Leibniz-Institute for Analytical Sciences (ISAS), 44139 Dortmund, Germany \\ ${ }^{3}$ Institute of Molecular Virology, ZMBE, Westfälische Wilhelms-University of Münster, 48149 Münster, Germany \\ ${ }^{4}$ Department of Dermatology and Boltzmann Institute for Immunobiology of the Skin, \\ Westfälische Wilhelms-University of Münster, 48149 Münster, Germany \\ ${ }^{5}$ Departments of Dermatology and Surgery, University of California San Francisco (UCSF), San Francisco, CA 94143, USA
}

Correspondence should be addressed to Micha Feld; micha.feld@med.uni-duesseldorf.de

Received 29 April 2013; Accepted 12 August 2013

Academic Editor: Richard Tucker

Copyright (C) 2013 Micha Feld et al. This is an open access article distributed under the Creative Commons Attribution License, which permits unrestricted use, distribution, and reproduction in any medium, provided the original work is properly cited.

\begin{abstract}
Proteinase-activated receptor-2 $\left(\mathrm{PAR}_{2}\right)$ is expressed by human leukocytes and participates in the development of inflammatory diseases. Recent studies demonstrated an ability of $\mathrm{PAR}_{2}$ agonist to enhance IFN $\gamma$-induced antiviral responses of human leukocytes. However, the precise cellular antiviral defense mechanisms triggered in leukocytes after stimulation with IFN $\gamma$ and/or PAR agonist remain elusive. Therefore, we aimed to identify neutrophil defense mechanisms involved in antiviral resistance. Here we demonstrated that $\mathrm{PAR}_{2}$ agonist enhanced IFN $\gamma$-related reduction of influenza A virus (IAV) replication in human neutrophils. $\mathrm{PAR}_{2}$-mediated decrease in IAV replication was associated with reduced NS-1 transcription. Moreover, $\mathrm{PAR}_{2}$-dependent neutrophil activation resulted in enhanced myeloperoxidase degranulation and extracellular myeloperoxidase disrupted IAV. The production of ROS was elevated in response to $\mathrm{PAR}_{2}$ activation. Interestingly, IFN $\gamma$ did not influence both effects: $\mathrm{PAR}_{2}$ agonist-triggered myeloperoxidase (MPO) release and reactive oxygen species (ROS) production, which are known to limit IAV infections. In contrast, orthomyxovirus resistance gene $\mathrm{A}(\mathrm{MxA})$ protein expression was synergistically elevated through $\mathrm{PAR}_{2}$ agonist and IFN $\gamma$ in neutrophils. Altogether, these findings emphasize two $\mathrm{PAR}_{2}$-controlled antiviral mechanisms that are independent of or modulated by IFN $\gamma$.
\end{abstract}

\section{Introduction}

The impact of proteinase-activated receptor- $2\left(\mathrm{PAR}_{2}\right)$ activation on inflammatory processes varies and depends on the stage of disease and the primary cell type(s) involved in disease progression $[1,2]$. Trypsin, tryptase, and pathogenderived proteases could trigger $\mathrm{PAR}_{2}$ activation [3]. However, these enzymes cause $\mathrm{PAR}_{2}$-dependent as well as $\mathrm{PAR}_{2}$-independent effects $[4,5]$. Moreover, trypsin-like serine proteases could assist influenza A replication via cleavage of viral hemagglutinin [6]. Together, these facts exclude the use of trypsin and tryptase as appropiate $\mathrm{PAR}_{2}$ activators in studies involving influenza A virus. Thus we used influenza A/FPV/Bratislava/79 (H7N7) containing a multibasiccleavage site, which efficiently replicates without the necessity of trypsin. Moreover, specific synthetic $\mathrm{PAR}_{2}$-activating peptides, used in our study, do not affect hemagglutinin maturation but reportedly serve as important tools for investigating the role of $\mathrm{PAR}_{2}$ activation in a wide range of anti-influenza responses.

Interferon- $\gamma$ (IFN $\gamma)$ regulates the cellular antiviral state and shapes the antiviral and inflammatory response [7]. 
Recent in vitro and in vivo studies revealed a cooperation between IFN $\gamma$ and $\mathrm{PAR}_{2}$ agonists in the induction of antiviral responses and in the regulation of the chemokine levels [8-10]. However, it remains unclear which cellular antiviral defence mechanism(s) in leukocytes are affected after concomitant IFN $\gamma$ and $\mathrm{PAR}_{2}$ agonist application.

Neutrophils participate in the defence against influenza A virus (IAV) infection. Although it is well established that neutrophils contribute to lung injury during IAV infection, neutropenia is associated with enhanced virus replication in lungs and high mortality [11]. Moreover, neutrophils limit spreading in the organism of IAV strains with intermediate or high virulence [12]. Human neutrophils express functional $\mathrm{PAR}_{2}[13,14]$, which regulates motility and bactericidal activity of neutrophils $[1,10]$. Although the $\mathrm{PAR}_{2}$-induced bactericidal activity is not enhanced in the presence of IFN $\gamma$ in neutrophils [10], $\operatorname{PAR}_{2}$ agonist and IFN $\gamma$ synergize boosting anti-influenza effects in human monocytes [8]. Nonetheless, the role of $\mathrm{PAR}_{2}$ and IFN $\gamma$ in neutrophils during IAV infection remains elusive.

Neutrophils possess a broad spectrum of weapons against viral and microbial pathogens including compounds of neutrophil granules (defensins, elastase, and some others), reactive oxygen species (ROS), and orthomyxovirus resistance gene $(\mathrm{Mx})$ proteins $[15,16]$. Thus, we investigated how $\mathrm{PAR}_{2}$ activation affects IAV replication in neutrophils and which defence mechanism(s) are activated. We also evaluated whether $\mathrm{PAR}_{2}$ agonist and IFN $\gamma$ synergize to strengthen the antiviral response.

\section{Material and Methods}

2.1. Materials. Human $\mathrm{PAR}_{2}$-activating peptide with the sequence trans-cinnamoyl-LIGRLO- $\mathrm{NH}_{2}$ (tcAP) and the reverse peptide with the sequence trans-cinnamoyl-OLRGIL$\mathrm{NH}_{2}$ (tcRP) were synthesized at the University of Calgary (Peptide Synthesis Facility, Dr. D. McMaster, Calgary, Canada; http://www.ucalgary.ca/peptides/) and used at a concentration of $10^{-4} \mathrm{M}$ as described previously [8]. Human recombinant IFN $\gamma$ was received from Peprotech (Hamburg, Germany) and used at a concentration of $200 \mathrm{U} / \mathrm{mL}$. The following antibodies were used: mouse anti-human $\beta$-actin (Sigma Aldrich); mouse monoclonal anti-MxA antibody (M143) which was a kind gift from the Department of Virology of the University of Freiburg and was used as described previously [17]. All cell culture reagents were obtained from PAA (Cölbe, Germany) or otherwise stated in the text.

2.2. Isolation and Culture of Neutrophils. Buffy coats from healthy adult human volunteers were obtained from the Deutsches Rotes Kreuz (Münster, Germany), and neutrophils were prepared as described previously [18]. Isolated neutrophils $\left(1-1.5 \times 10^{6}\right.$ cells $\left./ \mathrm{mL}\right)$ were allowed to recover in RPMI 1640 (Lonza) supplemented with 1\% L-glutamine, 1\% nonessential amino acids, $1 \%$ penicillin/streptomycin, and $0.9 \%$ fetal calf serum for at least $1 \mathrm{hr}$.

2.3. Virus and Infections. Avian influenza virus $\mathrm{A} / \mathrm{FPV} /$ Bratislava/79 (H7N7; FPV) was originally obtained from the virus strain collection of the Institute of Virology (JustusLiebig-University, Gießen, Germany). For infection, human neutrophils were washed with PBSi (PBS supplemented with $0.01 \% \mathrm{CaCl}_{2}, 0.01 \% \mathrm{MgCl}_{2}$, and $0.2 \%$ bovine serum albumin (BSA)) and infected with a multiplicity of infection of 0.75 . Therefore, the virus was diluted accordingly in PBSi and applied to the cells for $30 \mathrm{~min}$ at $37^{\circ} \mathrm{C}$ and $5 \% \mathrm{CO}_{2}$. Then, the inoculum was aspirated and replaced by RPMI 1640 supplemented with $2 \mathrm{mM}$ L-glutamine, $1 \%$ nonessential amino acids, $1 \%$ penicillin and streptomycin, $0.2 \% \mathrm{BSA}$, $0.01 \% \mathrm{CaCl}_{2}$, and $0.01 \% \mathrm{MgCl}_{2}$. For inhibitor studies, $1 \mathrm{mM}$ myeloperoxidase (MPO) inhibitor (Calbiochem) or vehicle was added to the medium. Subsequently, cells were stimulated with agonists or left untreated. Cells were incubated for $0-20 \mathrm{hrs}$ (as indicated in the text) at $37^{\circ} \mathrm{C}$ and $5 \% \mathrm{CO}_{2}$ depending on the readout system. In a second experimental approach, neutrophils were primed with agonists for $2 \mathrm{hrs}$ and, subsequently, infected with IAV for $30 \mathrm{~min}$ as described above. Following infection primed cells were rechallenged with agonists (b/a stimulation protocol) for $20 \mathrm{hrs}$. Only if stated in the text, the b/a stimulation protocol was applied.

2.4. Quantification of Neutrophil Degranulation. After recovery, neutrophils were treated for 2 hrs with the indicated agonists or used immediately without prestimulation. Then, cells were spun down and resuspended at a ratio of $1 \times 10^{6}$ cells per $100 \mu \mathrm{L}$ in PBS. Neutrophils were pretreated with $5 \mu \mathrm{g} / \mathrm{mL}$ of the degranulation-promoting agent Cytochalasin B (Sigma Aldrich) (for $5 \mathrm{~min}$ at $37^{\circ} \mathrm{C}$ ) and, subsequently, rechallenged with appropriate agonists for $30 \mathrm{~min}$ at $37^{\circ} \mathrm{C}$. Cells were removed by centrifugation, and the supernatant was analysed for elastase and MPO activity. To measure the elastase release, the supernatant was prediluted $1 / 100$ and incubated with $100 \mu \mathrm{g} / \mathrm{mL}$ alpha-1-antitrypsin $(\alpha 1 \mathrm{AT})$ for $30 \mathrm{~min}$ at $37^{\circ} \mathrm{C}$. Then, elastase $/ \alpha 1 \mathrm{AT}$ mixture was applied to PMN elastase ELISA (Abnova, Heidelberg, Germany). The assay was performed according to the manufacturer's instructions. To quantify the MPO levels, $100 \mu \mathrm{L}$ of degranulated supernatant

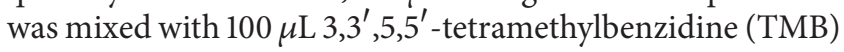
liquid substrate (Sigma Aldrich). Changes in the optical density at $630 \mathrm{~nm}$ were monitored for $20 \mathrm{~min}$.

2.5. IAV Disruption by Neutrophil Supernatant. Supernatant from degranulated neutrophils was prepared as described above. The virus was diluted to $1 \times 10^{6} \mathrm{PFU} / \mathrm{mL}$. Then, neutrophil supernatant and virus dilution were mixed in a ratio of $1: 1$ and supplemented with $1 \mathrm{mM} \mathrm{H}_{2} \mathrm{O}_{2}$ (Merck) or vehicle as indicated. After incubation for $1 \mathrm{hr}$ at $37^{\circ} \mathrm{C}$ and $5 \% \mathrm{CO}_{2}$, samples were collected and analysed in a standard plaque assay.

2.6. Measurement of Intracellular Reactive Oxygen Species (ROS). Intracellular generation of ROS was detected using the fluorescent dye 5-(and-6)-chloromethyl-2 ${ }^{\prime}, 7^{\prime}$-dichlorodihydrofluorescein diacetate (CM-H2DCFDA) (Invitrogen). To induce ROS production, neutrophils $\left(1.5 \times 10^{6}\right.$ cells $\left./ \mathrm{mL}\right)$ were stimulated with the indicated agonists in the absence of cytochalasin B. Thirty minutes before the stimulation was stopped, $5 \mu \mathrm{M}$ CM-H2DCFDA was added. Then, cells were 
put on ice, spun down at $4^{\circ} \mathrm{C}$, and washed with PBS. Finally, neutrophils were resuspended in PBS supplemented with $1 \%$ FCS, 2 mM EDTA, and 2\% paraformaldehyde and analysed with the FACScalibur and Cell Quest Pro software (BD Biosciences).

2.7. Calcium Mobilization Studies. Changes in intracellular calcium levels were measured as described previously [8, $14,15]$. Briefly, isolated neutrophils were washed, resuspended in HEPES-buffered salt solution $(140 \mathrm{mM} \mathrm{NaCl}$, $3 \mathrm{mM} \mathrm{KCl}, 0.4 \mathrm{mM} \mathrm{Na}_{2} \mathrm{HPO}_{4}, 10 \mathrm{mM}$ HEPES, $5 \mathrm{mM}$ glucose, and $1 \mathrm{mM} \mathrm{MgCl}_{2}(\mathrm{pH} 7.4)$ ) with or without $0.8 \mathrm{mM} \mathrm{CaCl}_{2}$, and incubated with $3.5 \mu \mathrm{M}$ Fura-2 acetoxymethyl for $30 \mathrm{~min}$ at $37^{\circ} \mathrm{C}$. Cells were washed twice, resuspended in HEPESbuffered salt solution with or without $0.8 \mathrm{mM} \mathrm{CaCl}_{2}$, and $\mathrm{PAR}_{2}$-triggered elevation in intracellular calcium levels was measured in a FluoroMaxx spectrophotometer (Yobin Yvon). For inhibitor studies, cells were pretreated with $100 \mu \mathrm{M} 2$ aminoethoxydiphenyl borate (2-APB) for $3 \mathrm{~min}$ before the $\mathrm{PAR}_{2}$ agonist was applied.

2.8. Real-Time RT-PCR. Steady-state levels of MxA, oligoadenylate synthetase (OAS), and the viral nonstructural protein (NS-1/2) were evaluated by real-time fluorescence detection using Absolute SYBR Green ROX mix (Applied Biosystems, Foster City, CA, USA). Reactions in duplicate were analysed in an ABI Prism 7300 sequence detector supplied with SDS 2.1 software (Applied Biosystems). Specific primer pairs were used: MxA forward, $5^{\prime}$-AGAGAAGGTGAGAAGCTGATCC- $3^{\prime}$, and reverse, $5^{\prime}$-TTCTTCCAGCTCCTTCTCTCTG- $3^{\prime}$; oligoadenylate synthetase (OAS) forward, $5^{\prime}$-GCTCCTACCCTGTGTGTGTGT-3' , and reverse, $5^{\prime}$-TGGTGAGAGGACTGAGGAAGA- $3^{\prime}$; NS-1/2 forward, $5^{\prime}$-GAGGACTTGAATGGAATGATAACA-3' ${ }^{\prime}$, and reverse, $5^{\prime}$-GTCTCACTTCTTCAATCAACCATC- $3^{\prime}$.

2.9. Immunoblot Analysis. Stimulated neutrophils were collected, disrupted in preheated $\left(100^{\circ} \mathrm{C}\right)$ lysing buffer $(4 \mathrm{M}$ urea, $0.5 \mathrm{M}$ Tris $\mathrm{pH} 6.8,25 \%$ glycerine, $10 \%$ SDS, and $0.005 \%$ bromophenol blue) supplemented with freshly prepared $1 \mathrm{x}$ protease inhibitor cocktail (Roche Diagnostics) and $200 \mathrm{mM}$ dithiothreitol, and boiled for $5 \mathrm{~min}$. Whole cell lysate preparations of stimulated neutrophils were separated by SDS-PAGE and transferred onto nitrocellulose membrane. To assess MxA expression $35 \mu \mathrm{g}$ of protein lysate was applied per lane. Densitometric analysis was performed using ImageJ software.

2.10. Statistical Analysis. Results are expressed as mean \pm SEM. At least three independent experiments were performed $(n \geq 3)$. Statistical evaluation was done by an analysis of variance and Student's $t$-test or Wilcoxon matched-pairs signed rank test. Significance was set at $P<0.05$.

\section{Results}

3.1. IAV Replication in Neutrophils Is Reduced by $P A R_{2}$ Agonist and IFN $\gamma$. Previously, we revealed that $\mathrm{PAR}_{2}$ and IFN $\gamma$ cooperate to interfere with IAV replication in human monocytes [8]. Here, we investigated whether such a cooperation also exists in neutrophils, as they appear to play an important role during IAV infections. Therefore, we aimed to confirm the replication of the avian IAV strain H7N7 in human neutrophils. Indeed, infection of neutrophils led to a timedependent upregulation of viral NS-1 mRNA after 2 and 4 hrs. In noninfected neutrophils, viral NS-1 mRNA was not detectable (Figure 1(a)). Next, we treated IAV-infected neutrophils with $\mathrm{PAR}_{2}$-tcAP, IFN $\gamma$, or a combination thereof and measured viral titers after $20 \mathrm{hrs}$. $\mathrm{PAR}_{2}$ agonist stimulation decreased IAV titers by $80 \pm 2 \%$, whereas IFN $\gamma$ treatment had no significant effect (Figure 1(b)). Concomitant stimulation with $\mathrm{PAR}_{2}$ agonist and IFN $\gamma$ reduced IAV progeny by 3-4fold (Figure 1(b)). To evaluate whether primed neutrophils are more resistant to IAV replication, we primed neutrophils with $\mathrm{PAR}_{2}$ agonist, IFN $\gamma$, or their combination for $2 \mathrm{hrs}$ before cells were infected with IAV and rechallenged cells after infection (b/a-stimulation). In this stimulation protocol, $\mathrm{PAR}_{2}$ and IFN $\gamma$ reduced viral titers by $68 \pm 4 \%$ and by $57 \pm$ $5 \%$, respectively (Figure $1(\mathrm{c})$ ). Combining $\mathrm{PAR}_{2}$ agonist and IFN $\gamma$ additively decreased IAV titers by approximately $86 \pm 2 \%$ (Figure 1(c)). Scrambled $\mathrm{PAR}_{2}$ peptide (tcRP) was used as control and did not affect viral titers (Figure 1(c)). Together, our data revealed that IAV replicates in neutrophils and that $\mathrm{PAR}_{2}$ agonist and IFN $\gamma$ reduce IAV titers.

3.2. $P A R_{2}$ Activation Triggers Degranulation and Production of Reactive Oxygen Species (ROS) in Neutrophils. Myeloperoxidase (MPO) as well as other compounds of azurophil granules were demonstrated to have anti-influenza activity $[19,20]$ and, thus, may contribute to host protective rather than harmful functions. $\mathrm{PAR}_{2}$-AP was shown to increase plasma MPO activity indicating enhanced neutrophil degranulation in mice [21]. Therefore, we analysed whether stimulation with $\mathrm{PAR}_{2}$-tcAP or IFN $\gamma$ triggers human neutrophil degranulation of azurophil granules in vitro. In our preliminary experiments, where neutrophils (app. $4 \times 10^{6}$ cells $/ 100 \mu \mathrm{L}$ ) were primed with $\mathrm{PAR}_{2}$ agonist for $2 \mathrm{hrs}$, a second dose of $\mathrm{PAR}_{2}$ agonist elicited the release of elastase. However, variations in the magnitudes of the effect did not allow this effect of $\mathrm{PAR}_{2}$ agonist to reach statistical significance (unpublished observations).

In contrast, preactivation of neutrophils with cytochalasin $\mathrm{B}$ led to a robust elevation of elastase and MPO release after $\mathrm{PAR}_{2}$ activation. Basal release of MPO and elastase in cytochalasin B primed neutrophils was determined as $26.9 \pm$ $4.6 \mathrm{mU}$ and $113.6 \pm 21.0 \mathrm{ng} / \mathrm{mL}$, respectively (Figure 2(a)). Further addition of $\mathrm{PAR}_{2}$-tcAP enhanced extracellular MPO $(86.5 \pm 19.3 \mathrm{mU})$ and elastase $(265.8 \pm 76.4 \mathrm{ng} / \mathrm{mL})$ levels significantly, but degranulation was unaffected by IFN $\gamma$. Concomitant stimulation with $\mathrm{PAR}_{2}$ agonist and IFN $\gamma$ failed to overcome the effect induced by $\mathrm{PAR}_{2}$-tcAP alone.

$\mathrm{PAR}_{2}$-tcAP primed, then cytochalasin $\mathrm{B}$ treated and rechallenged neutrophils (see "Quantification of Neutrophil degranulation" in Material and Methods Section for details) behaved in different way. Applying the b/a stimulation, the second $\mathrm{PAR}_{2}$ activation resulted in significantly less elevated MPO levels $(87.9 \pm 20.4 \mathrm{mU})$ as compared to $128.6 \pm$ $24.0 \mathrm{mU}$ in nonpreactivated cells (Figure 2(b)). However, this reduction was not detected in neutrophils activated with both $\mathrm{PAR}_{2}$ agonist and IFN $\gamma$ (Figure 2(b)). 


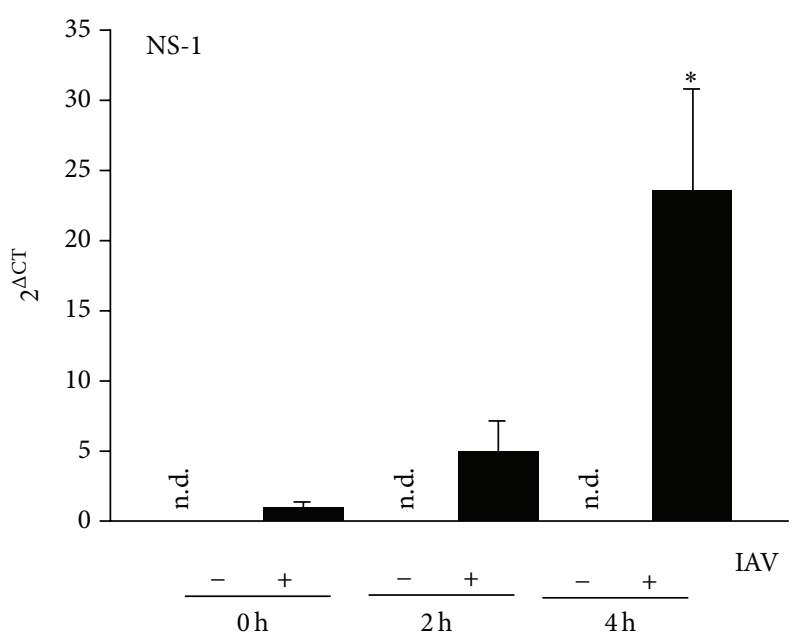

(a)

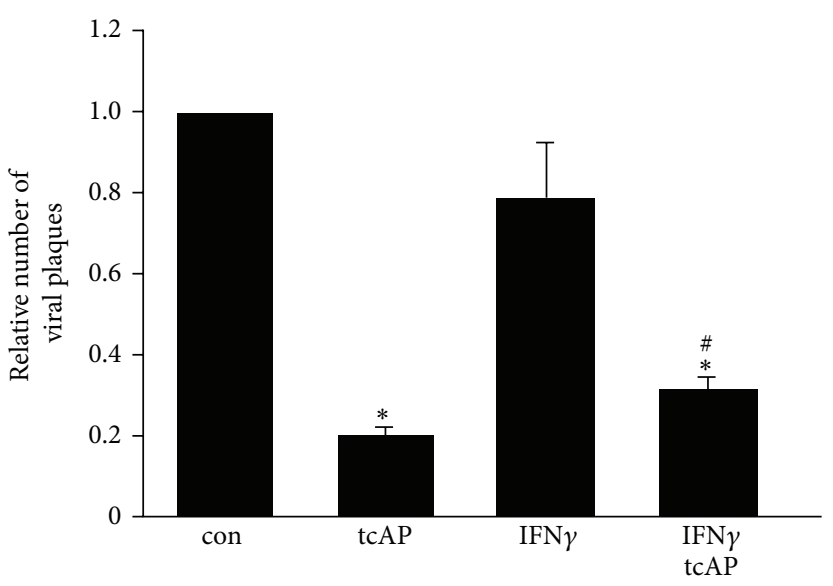

(b)

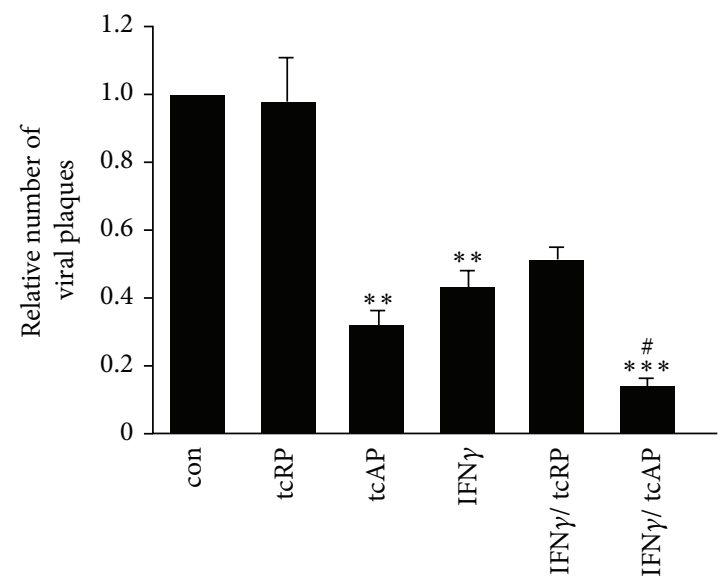

(c)

FIGURE 1: IAV replication in neutrophils was restricted by $\mathrm{PAR}_{2}$ activation and IFN $\gamma$. (a) Replication of IAV in neutrophils was determined by detection of NS-1 mRNA levels at different time points after infection. At 4 hrs, a significant induction of NS-1 mRNA expression was revealed. In noninfected neutrophils NS-1 mRNA was not detectable. (b) IAV-infected neutrophils were treated with agonists as indicated for 20 hrs. Analysis of IAV titers showed a significant reduction in $\mathrm{PAR}_{2}$ agonist and $\mathrm{PAR}_{2}$ agonist/IFN $\gamma$ treated neutrophils. (c) In cells that were primed with agonists for $2 \mathrm{hrs}$, infected with IAV for $30 \mathrm{~min}$, and rechallenged with agonists for 20 hrs, both PAR 2 agonist and IFN $\gamma$ decreased viral replication. Moreover, combining $\mathrm{PAR}_{2}$ agonist and IFN $\gamma$ further reduced IAV titers as compared to both agonists alone. For student's $t$-test: ${ }^{\# * *} P<0.05 ;{ }^{* *} P<0.01 ;{ }^{* * *} P<0.005$. The symbol $*$ marks the significance as compared to control and the symbol \# as compared to IFN $\gamma$ sample.

Because degranulation is often triggered by $\mathrm{Ca}^{2+}$ signaling, we also investigated the contribution of $\mathrm{Ca}^{2+}$ fluxes to $\mathrm{PAR}_{2}$-induced degranulation. $\mathrm{PAR}_{2}$ agonist induced a rapid increase in intracellular $\mathrm{Ca}^{2+}$ signaling in both $\mathrm{Ca}^{2+}$-free or $\mathrm{Ca}^{2+}$-supplemented buffer. However, extracellular $\mathrm{Ca}^{2+}$ boosted $\mathrm{PAR}_{2}$ agonist-induced intracellular calcium signals by 3fold as compared to extracellular $\mathrm{Ca}^{2+}$ starvation (Figure 2(c), green columns). However, $\mathrm{PAR}_{2}$-induced release of azurophil granules was independent of additional extracellular $\mathrm{Ca}^{2+}$ (data not shown). 2-APB is known as an inhibitor of InsP3-induced $\mathrm{Ca}^{2+}$ release and, probably, concomitant $\mathrm{Ca}^{2+}$ entry [22]. 2-APB inhibited $\mathrm{PAR}_{2}$-induced $\mathrm{Ca}^{2+}$ release
(Figures 2(c) and 2(d)) and, subsequently, reduced degranulation of azurophil granules as measured by elastase release (Figure 2(e)).

Reactive oxygen species (ROS) shape the inflammatory response during IAV infections [23]. In neutrophils, $\mathrm{PAR}_{2}$ tcAP, without any priming with cytochalasin $\mathrm{B}$, induced ROS production that peaked at $2 \mathrm{hrs}$ and then declined to baseline levels within $20 \mathrm{hrs}$. At $2 \mathrm{hrs}, \mathrm{PAR}_{2}$ significantly upregulated ROS levels by $1.6 \pm 0.2$-fold as compared to controls. However, combination of $\mathrm{PAR}_{2}$ agonist and IFN $\gamma$ was not more potent in induction of ROS than $\mathrm{PAR}_{2}$-tcAP alone. IFN $\gamma$ alone did not affect ROS production in neutrophils (Figure 2(f)). Together, our data indicated a regulatory role 


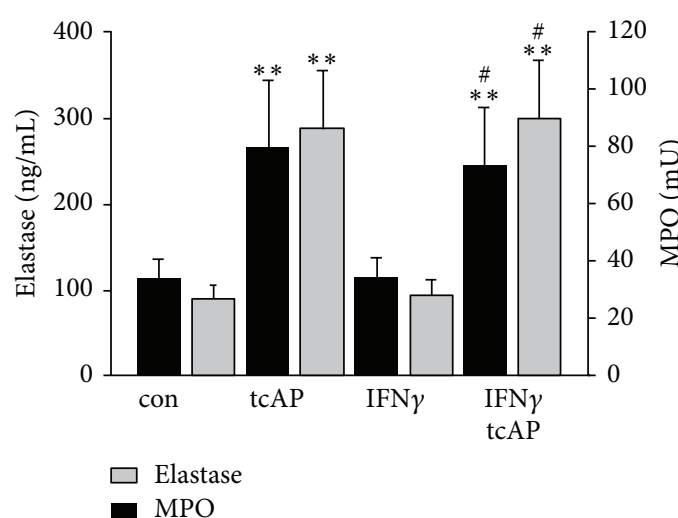

(a)

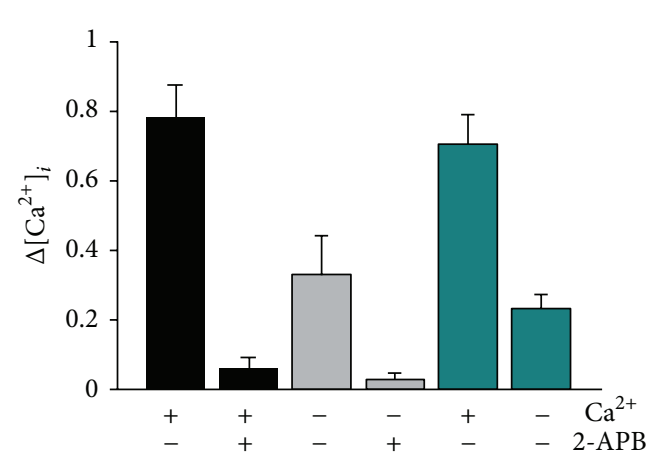

(c)

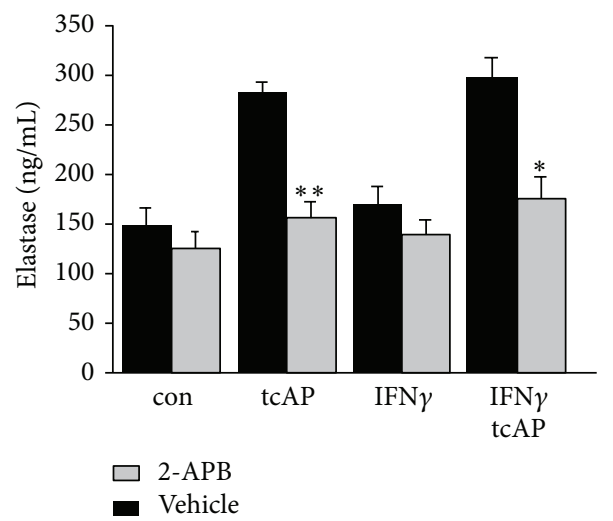

(e)

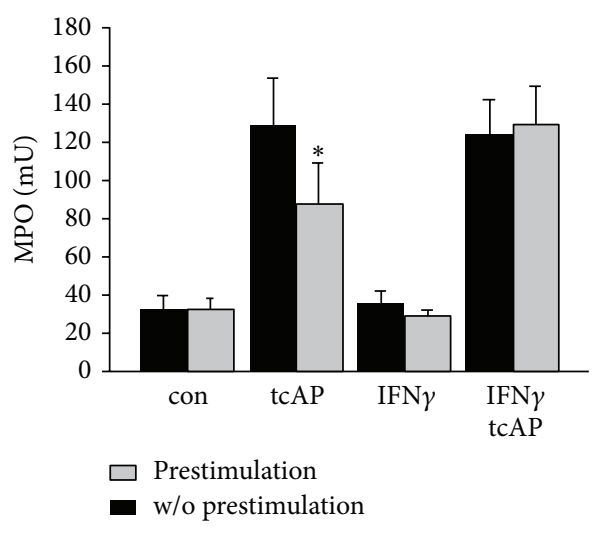

(b)

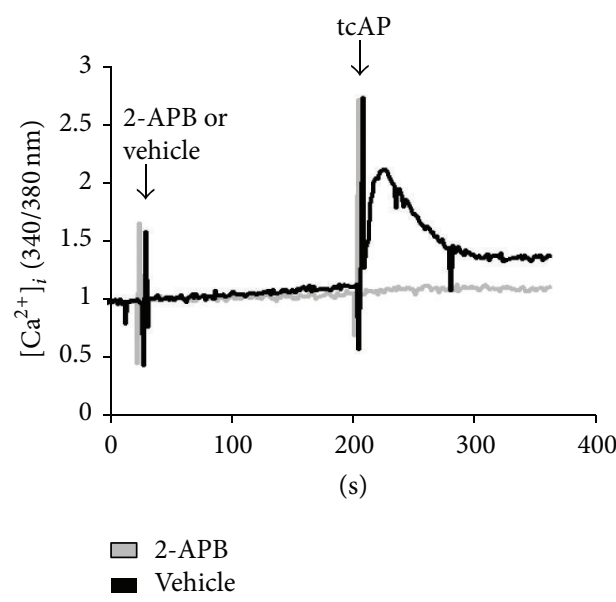

(d)

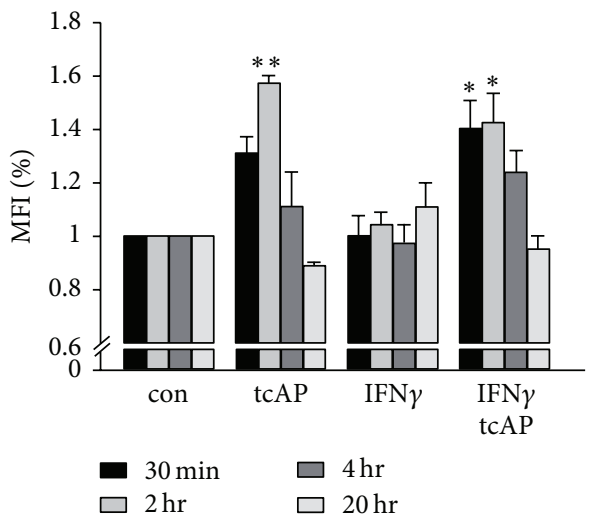

(f)

FIgURE 2: $\mathrm{PAR}_{2}$ stimulation induced neutrophil degranulation in a $\mathrm{Ca}^{2+}$-dependent manner and upregulated ROS production. Neutrophils were treated as described in Material and Methods Section. (a) After stimulation with $\mathrm{PAR}_{2}$ agonist and IFN $\gamma$, the concentration of MPO and elastase was quantified in cytochalasin B primed neutrophils. (b) Comparing MPO levels in cytochalasin B primed neutrophils that were either pretreated with agonists (b/a-stimulation) or not showed a reduction in $\mathrm{PAR}_{2}$ agonist stimulated neutrophils. Concomitant stimulation with $\mathrm{PAR}_{2}$-agonist and IFN $\gamma$ induced similar MPO levels in both pretreated and nonpretreated cells. (c, d) Neutrophils were loaded with Fura-2 AM (30 min), washed, and then $\mathrm{PAR}_{2}$ agonist was added, and calcium mobilization was investigated. The availability of extracellular $\mathrm{Ca}^{2+}$ led to increased intracellular calcium levels after $\mathrm{PAR}_{2}$ agonist application. 2-APB almost completely blocked intracellular Ca ${ }^{2+}$ fluxes, independent of extracellular $\mathrm{Ca}^{2+}$. (e) Pretreatment of neutrophils with 2-APB prevented $\mathrm{PAR}_{2}$ agonist induced elastase release. (f) Changes in ROS levels were measured using a fluorescent substance (CM-H2DCFDA) that was added 30 min before the stimulation was stopped (see Material and Methods Section). Only at early time points, $\mathrm{PAR}_{2}$ agonist elevated ROS level as measured by changes of the MFI. IFN $\gamma$ did not induce ROS upregulation. For student's $t$-test: ${ }^{*, *} P<0.05 ;{ }^{* *} P<0.01$. The symbol $*$ marks the significance as compared to control and the symbol \# as compared to IFN $\gamma$ sample. 
for $\mathrm{PAR}_{2}$, but not for IFN $\gamma$, in neutrophil degranulation of azurophil granules and ROS production.

3.3. MPO Activity Disrupts IAV, but MPO Inhibition Is not Sufficient to Reverse PAR $R_{2}$ Agonist-Induced Reduction of IAV Replication. MPO and ROS are required for extracellular disruption of IAV [20]. Therefore, we hypothesized that degranulation fluid (DF) from $\mathrm{PAR}_{2}$-activated neutrophils may disrupt IAV. Neutrophils were treated with $\mathrm{PAR}_{2}$ agonist, IFN $\gamma$, or their combination, and the DF was collected. In the presence of $\mathrm{H}_{2} \mathrm{O}_{2}$, DF from $\mathrm{PAR}_{2}$ agonist-treated neutrophils decreased IAV titers by 20 -fold $(95 \pm 5 \%)$ as compared to controls, whereas DF from IFN $\gamma$-stimulated neutrophils only marginally decreased viral titers by $14 \pm 1.5 \%$ (Figures $3(\mathrm{a}$ ) and $3(\mathrm{~b})$ ). DF from $\mathrm{PAR}_{2}$ agonist and IFN $\gamma$ costimulated neutrophils In the presence of $\mathrm{H}_{2} \mathrm{O}_{2}$, the DF from PAR2 agonist and IFN $\gamma$ co-stimulated neutrophils reduced viral titers by 20 -fold as compared to controls. In the absence of $\mathrm{H}_{2} \mathrm{O}_{2}$, DF did not reduce viral titers (data not shown). Of note, purified elastase failed to disrupt IAV (data not shown).

To further specify the role of MPO and $\mathrm{H}_{2} \mathrm{O}_{2}$ in neutrophil response against IAV, we treated IAV-infected neutrophils with a specific MPO inhibitor prior to stimulation with $\mathrm{PAR}_{2}$ agonist, IFN $\gamma$, or their combination. In IAVinfected untreated neutrophils, MPO inhibition increased viral titers by approximately 4 -fold (Figure 3(c)). It is worth to notice that $\mathrm{PAR}_{2}$ activation significantly decreased viral titers 2 -fold (50 $\pm 10 \%)$ even in the presence of the MPO inhibitor (Figure 3(c)). In contrast, IFN $\gamma$ did not reduce viral titers in neutrophils treated with MPO inhibitor. The combination of $\mathrm{PAR}_{2}$-tcAP and IFN $\gamma$ showed a trend to decrease viral progeny even in the absence of functional MPO.

We next analysed whether reduction of viral progeny originated from intracellular events. Therefore, neutrophils were infected with IAV. Further, viral NS-1 mRNA synthesis was measured as a marker for virus replication. In the case of $\mathrm{PAR}_{2}$ agonist as well as combined $\mathrm{PAR}_{2}$ agonist and/IFN $\gamma$ costimulation viral NS-1 mRNA levels were decreased by $70 \pm 10 \%$ and $50 \pm 18 \%$, respectively (Figure $3(\mathrm{~d})$ ). Again, IFN $\gamma$ alone had no effect on reduction of viral NS-1 mRNA synthesis (Figure 3(d)).

Thus, $\mathrm{PAR}_{2}$ agonist-induced disruption of IAV is associated with the MPO- $\mathrm{H}_{2} \mathrm{O}_{2}$ axis and intracellular antiviral mechanisms interfering with IAV gene transcription, indicating at least two $\mathrm{PAR}_{2}$-regulated antiviral mechanisms.

3.4. $\mathrm{PAR}_{2}$ Agonist Stimulation Affects IFN $\gamma$-Induced $M x A$ Expression in Human Neutrophils. We investigated the regulation of OAS and MxA levels. IFN $\gamma$ triggered OAS mRNA expression at $4 \mathrm{hrs}$ and $16 \mathrm{hrs}$ by $61 \pm 18$-fold and $197 \pm 88$-fold, respectively, as compared to controls (Figures 4(a) and 4(b)). When applied together, PAR $_{2}$ agonist and IFN $\gamma$ induced OAS mRNA expression at $4 \mathrm{hrs}$ and $16 \mathrm{hrs}$ by $56 \pm 20$-fold and $210 \pm 96$-fold, respectively (Figures 4(a) and $4(\mathrm{~b})) . \mathrm{PAR}_{2}$ agonist alone did not induce either OAS or MxA expression (Figures 4(a) and 4(b)). IFN $\gamma$ induced MxA mRNA levels by $48 \pm 13$-fold ( $4 \mathrm{hrs}$ ) and $20 \pm 7$-fold (16 hrs) as compared to controls. Concomitant stimulation with $\mathrm{PAR}_{2}$ agonist and IFN $\gamma$ enhanced MxA expression by
$25 \pm 6$-fold at $4 \mathrm{hrs}$ and $46 \pm 11$-fold at $16 \mathrm{hrs}$ (Figures 4 (a) and $4(\mathrm{~b})$ ) as compared to controls. Since mRNA upregulation not necessarily leads to protein upregulation, the mRNA data were further verified by analysis of MxA on protein levels. As shown in Figures 4(c) and 4(d), the analysis of MxA protein expression after agonist stimulation resembled the expression profile observed on mRNA level. However, only the concomitant stimulation with $\mathrm{PAR}_{2}$ agonist and IFN $\gamma$ upregulated the MxA protein expression significantly (Figures 4(c) and 4(d)). Although MxA was also slightly increased after IFN $\gamma$ treatment alone, this effect never reached statistical significance. In two samples out of six, MxA was just barely detectable after IFN $\gamma$ stimulation (data not shown). However, in other samples MxA expression was detectable and just slightly enhanced after IFN $\gamma$ stimulation (Figures 4(c) and $4(\mathrm{~d})$ ).

Thus, $\mathrm{PAR}_{2}$ agonist stimulation appears to be an important factor enhancing IFN $\gamma$-induced expression of MxA.

\section{Discussion}

The central hypothesis of our current work focuses on the role of $\mathrm{PAR}_{2}$-mediated degranulation-dependent antiviral responses and $\mathrm{PAR}_{2}$-induced intracellular defence mechanisms. Therefore, we investigated whether $\mathrm{PAR}_{2}$ activates MPO release or triggers intracellular events that interfere with transcription of viral genes. We also explored whether antiviral defence mechanisms (e.g., MxA) might be regulated by $\mathrm{PAR}_{2}$ agonist and IFN $\gamma$.

First of all, we proved the ability of $\mathrm{PAR}_{2}$ and IFN $\gamma$ to synergize reducing IAV replication in human neutrophils (Figure 1). Indeed, simultaneous pretreatment with both agonists followed by their coapplication after infection was more effective in the reduction of IAV replication than any of agonists alone (Figure $1(\mathrm{c})$ ). Moreover, $\mathrm{PAR}_{2}$ agonist application, but not IFN $\gamma$, reduced IAV amplification in infected human neutrophils even without pretreatment (Figure 1(b)), suggesting different antiviral activities of IFN $\gamma$ and $\mathrm{PAR}_{2}$ agonist. We hypothesized that $\mathrm{PAR}_{2}$ elicits immediate effects based on neutrophil degranulation, whereas the antiviral action of IFN $\gamma$ is time-delayed. Thus, further, we investigated cellular anti-influenza defence mechanisms triggered by both substances.

Neutrophilic MPO was shown to possess anti-pathogenic activity in the presence of $\mathrm{H}_{2} \mathrm{O}_{2}$ [20]. Moreover, $\mathrm{PAR}_{2}$-AP application was demonstrated to enhance MPO release in mice [21]. However, it remained unclear whether $\mathrm{PAR}_{2}$ agonists directly induce neutrophil degranulation and whether released MPO inactivates or disrupts the IAV strain H7N7. We revealed that $\mathrm{PAR}_{2}$ agonist application triggers $\mathrm{Ca}^{2+}$ dependent degranulation of human neutrophils and, thus, enhances MPO and elastase release (Figure 2). To measure degranulation, we pretreated neutrophils with cytochalasin B. Cytochalasin B is an artificial substance, which mimics neutrophil priming potentially via induction of a state of GPCRs reactivation [24]. However, in preliminary studies, rechallenge of $\mathrm{PAR}_{2}$ agonist-primed neutrophils also showed a trend of elevated elastase levels indicating that degranulation may partially occur without cytochalasin B pretreatment 


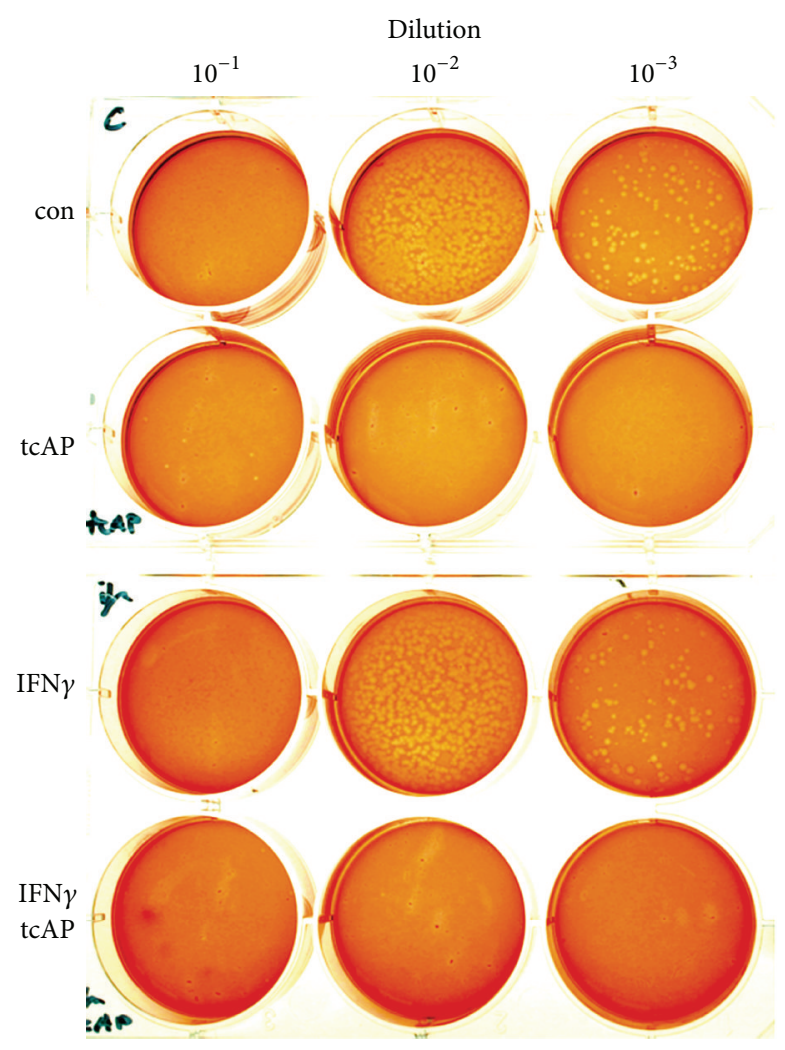

(a)

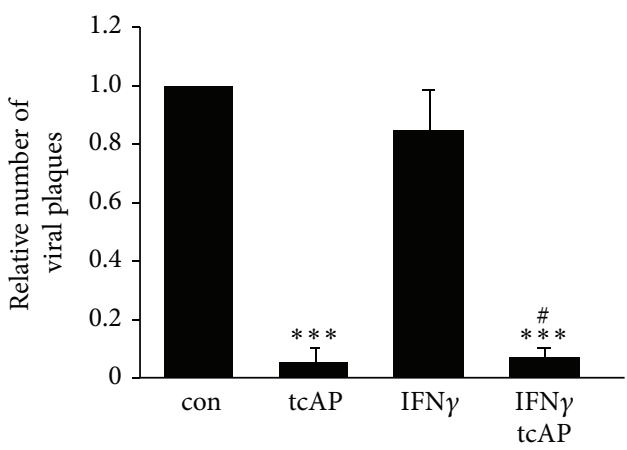

(b)

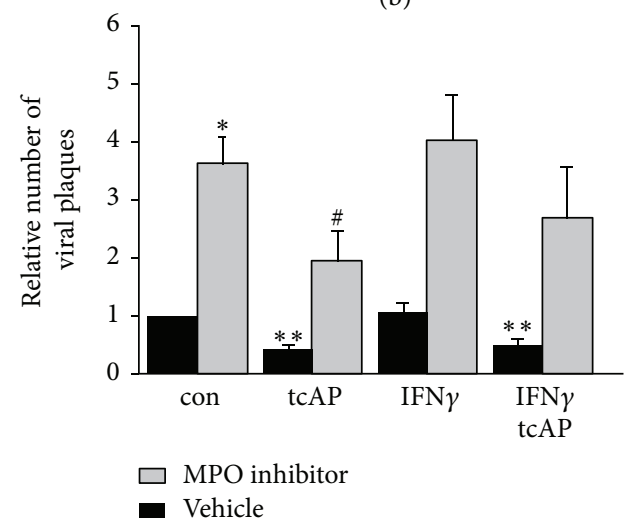

(c)

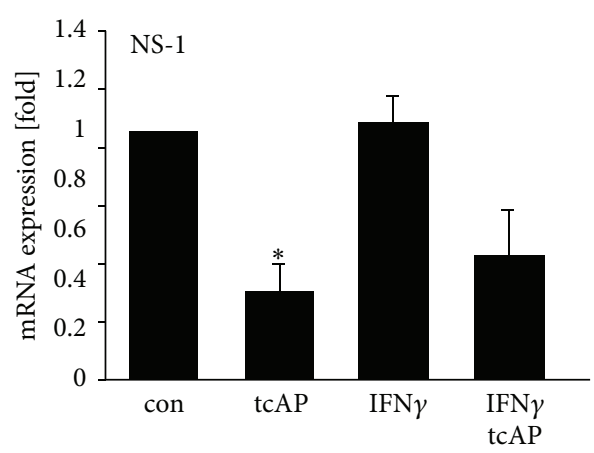

(d)

FIGURE 3: Influenza titers were controlled through extracellular MPO and on transcriptional level through $\mathrm{PAR}_{2}$. (a, b) DF from stimulated neutrophils was supplemented with $\mathrm{H}_{2} \mathrm{O}_{2}$, and the virucidal activity was determined. DF from $\mathrm{PAR}_{2}$ agonist treated neutrophils disrupted IAV. (c) Application of a MPO inhibitor enhanced viral titers. Interestingly, despite MPO inhibition, $\mathrm{PAR}_{2}$ activation reduced viral replication in neutrophils. (d) Analysis of viral gene replication displayed reduced NS-1 mRNA expression in $\mathrm{PAR}_{2}$ agonist stimulated neutrophils. IFN $\gamma$ had no effect on viral replication. For student's $t$-test: ${ }^{\#, *} P<0.05$; ${ }^{* *} P<0.01$; ${ }^{* * *} P<0.005$. The symbol $*$ marks the significance as compared to control and the symbol \# as compared to IFN $\gamma$ sample.

(unpublished data). Interestingly, $\mathrm{PAR}_{2}$ agonist stimulation, without cytochalasin $\mathrm{B}$ pretreatment, was capable of enhancing ROS production by human neutrophils (Figure 2(f)), amongst which $\mathrm{H}_{2} \mathrm{O}_{2}$ is the substrate for MPO. Moreover, we demonstrated that DF derived from $\mathrm{PAR}_{2}$ agonist-activated neutrophils contains MPO and disrupts extracellular IAV (Figure 3(a)), indicating a MPO-dependent anti-influenza action. In contrast, IFN $\gamma$ failed to enhance $\mathrm{PAR}_{2}$-triggered MPO release, and ROS production (Figure 2). Thus, $\mathrm{PAR}_{2}$ appears to induce an anti-influenza defence mechanism in human neutrophils based on degranulation, MPO release and ROS production. However, these mechanisms are clearly independent of and not regulated by IFN $\gamma$ and, thus, represent no cross-point regarding simultaneous $\mathrm{PAR}_{2}$ and IFN $\gamma$ antiviral action.

Although we demonstrated a substantial role for MPO in influenza disruption (Figure 3(a)), application of a MPO inhibitor did not completely reverse the downregulation of intracellular IAV replication in $\mathrm{PAR}_{2}$ agonist-activated neutrophils (Figures 3(b) and 3(c)), suggesting the existence of 


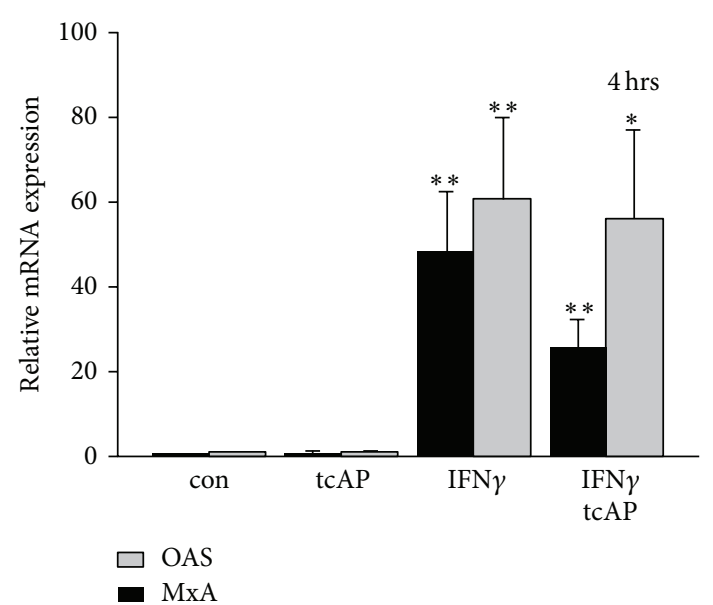

(a)

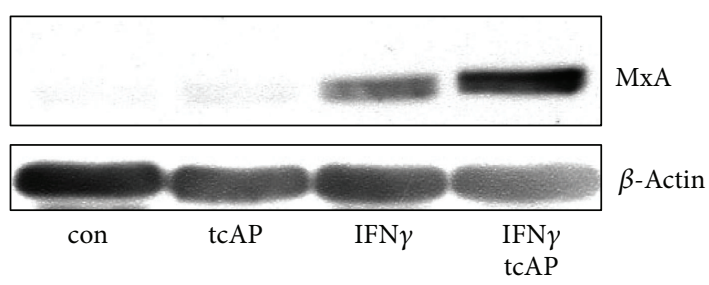

(c)

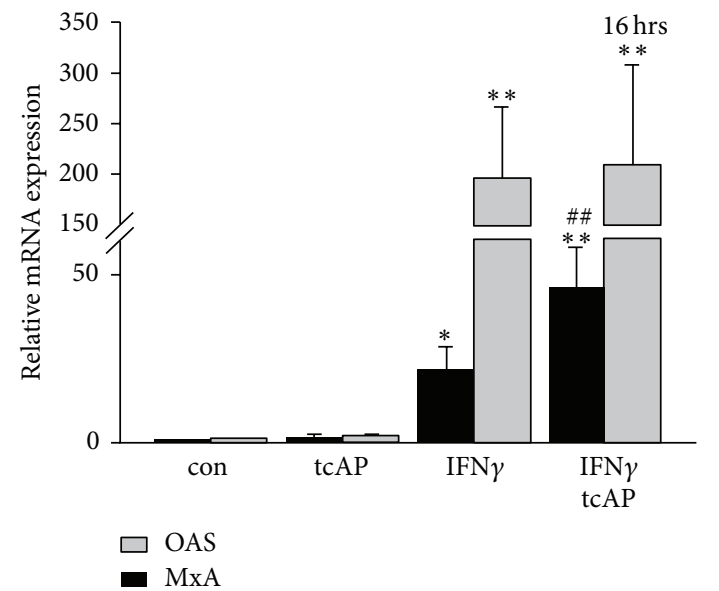

(b)

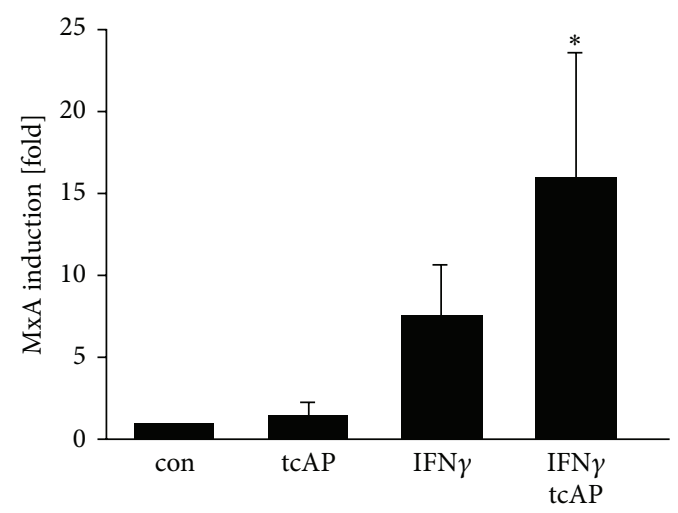

(d)

Figure 4: Regulation of MxA and OAS expression. (a, b) IFN $\gamma$-induced expression of OAS remained unaffected after application of PAR 2 agonist. But $\mathrm{PAR}_{2}$ agonist synergizes with IFN $\gamma$ to elevate MxA expression at $16 \mathrm{hrs}$, although this effect was not evident at early time points (4 hrs). (c, d) MxA expression was further analysed on protein level. Similar to mRNA results, concomitant stimulation with PAR $_{2}$ agonists and IFN $\gamma$ induced MxA protein (at $20 \mathrm{hrs}$ time point). In contrast, IFN $\gamma$ upregulated MxA only slightly and nonsignificantly. For students $t$-test: ${ }^{\#, *} P<0.05 ;{ }^{* *} P<0.01$. The symbol $*$ marks the significance as compared to control and the symbol \# as compared to IFN $\gamma$ sample. (d) Densitometric results were received for Western blot samples. Wilcoxon matched-pair signed rank test was applied for analysis: ${ }^{*} P<0.05$ as compared to control.

a redundant mechanism(s) that are controlled by $\mathrm{PAR}_{2}$. For example, the defensin, cathelicidin LL37, which is stored in neutrophil secondary granules, has been shown to exert antiinfluenza activity [25]. Moreover, $\mathrm{PAR}_{2}$ agonist application also reduced NS-1 production in IAV infected neutrophils (Figure 3(d)), further pointing to $\mathrm{PAR}_{2}$-mediated transcriptional regulation during virus replication.

IFN $\gamma$ application as a pretreatment and during infection (b/a stimulation) was able to reduce IAV replication in human neutrophils (Figure 1(c)). Moreover, in the b/a stimulation model, concomitant IFN $\gamma$ and $\mathrm{PAR}_{2}$ stimulation reduced IAV amplification in human neutrophils as compared to other stimulations (Figure 1(c)). Thus, antiviral mechanisms might require the presence of both $\mathrm{PAR}_{2}$ agonist and IFN $\gamma$. Indeed, application of $\mathrm{PAR}_{2}$ agonist together with IFN $\gamma$ resulted in stronger induction of MxA mRNA expression as compared to the stimulation with IFN $\gamma$ alone (Figure 4(b)). Antiviral MxA, classically inducible by type I interferons [26], was demonstrated to be elevated by IFN $\gamma$ on transcriptional level
[27]. To our knowledge, the detection of MxA protein upon IFN $\gamma$ stimulation remains elusive. Although we confirmed the induction of MxA mRNA upon IFN $\gamma$ treatment, we found variations in the MxA protein expression amongst the investigated donors. These variations could not be explained by the Western blot artefacts since the experimental protocol was kept constant during all the time. Only combined $\mathrm{PAR}_{2}$ agonist/IFN $\gamma$ stimulation significantly raised MxA protein levels in all investigated samples revealing a potential backup system for type I interferons for efficient fight against IAV infections intracellularly. $2^{\prime}-5^{\prime}$ oligoadenylate synthetase (OAS) also participates in cellular defence against RNA viruses and could be induced by IFN $\gamma[26,28]$. But OAS expression was not affected by $\mathrm{PAR}_{2}$ agonist application even in combination with IFN $\gamma$ (Figures 4(a) and 4(b)). Our data suggests that $\mathrm{PAR}_{2}$ shapes the antiviral response through activation of a defined set of defence mechanisms.

In summary, our data demonstrate that $\mathrm{PAR}_{2}$ agonist and IFN $\gamma$ synergize to reduce IAV progeny in human neutrophils. 
Enhanced MxA production is revealed as a cellular antiviral mechanism, which is synergistically activated by $\mathrm{PAR}_{2}$ agonist and IFN $\gamma$ in human neutrophils. However, in neutrophils $\mathrm{PAR}_{2}$ agonist controls IFN $\gamma$-independent antiviral mechanism(s) such as enhanced MPO release, ROS production, and reduction of viral gene transcription.

$\begin{array}{ll}\text { Abbreviations } \\ \text { 2-APB: } & \text { 2-Aminoethoxydiphenyl borate } \\ \alpha 1 \mathrm{AT}: & \text { Alpha-1-antitrypsin } \\ \mathrm{AP}: & \text { Activating peptide } \\ \text { b/a: } & \text { Before/after } \\ \mathrm{DF}: & \text { Degranulated fluid } \\ \mathrm{IAV}: & \text { Influenza A virus } \\ \mathrm{IFN} \gamma: & \text { Interferon gamma } \\ \mathrm{MPO}: & \text { Myeloperoxidase } \\ \mathrm{mU}: & \text { Milli units } \\ \mathrm{MxA}: & \text { Orthomyxovirus resistance protein A } \\ \mathrm{OAS}: & \text { Oligoadenylate synthetase } \\ \mathrm{PAR} & \text { Proteinase-activated receptor-2 } \\ \mathrm{ROS}: & \text { Reactive oxygen species } \\ \mathrm{RP}: & \text { Reverse peptide } \\ \text { tc: } & \text { Trans-cinnamoyl. }\end{array}$

\section{Conflict of Interests}

The authors of this paper declare no conflict of interests associated with data presented in the manuscript.

\section{Authors' Contribution}

Micha Feld designed the study, performed experiments, analysed data, and wrote the manuscript. Victoria Shpacovitch performed experiments and wrote the draft of the manuscript. Christina Ehrhardt, Tobias Goerge, and Michaela Fastrich performed experiments. Stephan Ludwig and Martin Steinhoff designed the study and reviewed the paper.

\section{Acknowledgments}

This work was supported by the IMF Muenster FE 110905 (to Micha Feld) and SH 120709 (to Victoria Shpacovitch), Deutsche Forschungsgemeinschaft (STE 1014/3-1 to Martin Steinhoff), IZKF Muenster (Stei3/034/09 to Martin Steinhoff), and Weston-Havens Foundation San Francisco (to Martin Steinhoff). The research fellow position of Victoria Shpacovitch in Leibniz Institute for Analytical Sciences (ISAS) is supported by SFB 876 Project B2.

\section{References}

[1] V. Shpacovitch, M. Feld, M. D. Hollenberg, T. A. Luger, and M. Steinhoff, "Role of protease-activated receptors in inflammatory responses, innate and adaptive immunity," Journal of Leukocyte Biology, vol. 83, no. 6, pp. 1309-1322, 2008.

[2] V. Shpacovitch, M. Feld, N. W. Bunnett, and M. Steinhoff, "Protease-activated receptors: novel PARtners in innate immunity," Trends in Immunology, vol. 28, no. 12, pp. 541-550, 2007.
[3] M. Steinhoff, J. Buddenkotte, V. Shpacovitch et al., "Proteinaseactivated receptors: transducers of proteinase-mediated signaling in inflammation and immune response," Endocrine Reviews, vol. 26, no. 1, pp. 1-43, 2005.

[4] R. Corteling, O. Bonneau, S. Ferretti, M. Ferretti, and A. Trifilieff, "Differential DNA synthesis in response to activation of protease-activated receptors on cultured guinea-pig tracheal smooth muscle cells," Naunyn-Schmiedeberg's Archives of Pharmacology, vol. 368, no. 1, pp. 10-16, 2003.

[5] M. D. Hollenberg, "Physiology and pathophysiology of proteinase-activated receptors (PARs): proteinases as hormone-like signal messengers: PARs and more," Journal of Pharmacological Sciences, vol. 97, no. 1, pp. 8-13, 2005.

[6] J. Stech, H. Garn, M. Wegmann, R. Wagner, and H.-D. Klenk, "A new approach to an influenza live vaccine: modification of the cleavage site of hemagglutinin," Nature Medicine, vol. 11, no. 6, pp. 683-689, 2005.

[7] K. Schroder, P. J. Hertzog, T. Ravasi, and D. A. Hume, "Interferon- $\gamma$ : an overview of signals, mechanisms and functions," Journal of Leukocyte Biology, vol. 75, no. 2, pp. 163-189, 2004.

[8] M. Feld, V. M. Shpacovitch, C. Ehrhardt et al., "Agonists of proteinase-activated receptor- 2 enhance IFN- $\gamma$-inducible effects on human monocytes: role in influenza A infection," The Journal of Immunology, vol. 180, no. 10, pp. 6903-6910, 2008.

[9] K. Khoufache, F. Lebouder, E. Morello et al., "Protective role for protease-activated receptor-2 against influenza virus pathogenesis via an IFN- $\gamma$-dependent pathway," The Journal of Immunology, vol. 182, no. 12, pp. 7795-7802, 2009.

[10] V. M. Shpacovitch, M. Feld, D. Holzinger et al., "Role of proteinase-activated receptor-2 in anti-bacterial and immunomodulatory effects of interferon- $\gamma$ on human neutrophils and monocytes," Immunology, vol. 133, no. 3, pp. 329-339, 2011.

[11] M. Tate, Y. M. Deng, J. E. Jones, G. P. Anderson, A. G. Brooks, and P. C. Reading, "Neutrophils ameliorate lung injury and the development of severe disease during influenza infection," The Journal of Immunology, vol. 183, no. 11, pp. 7441-7450, 2009.

[12] M. Tate, L. J. Ioannidis, B. Croker, L. E. Brown, A. G. Brooks, and P. C. Reading, "The role of neutrophils during mild and severe influenza virus infections of mice," PLOS ONE, vol. 6, no. 3, Article ID el7618, 2011.

[13] G. L. Howells, M. G. Macey, C. Chinni et al., "Proteinaseactivated receptor-2: expression by human neutrophils," Journal of Cell Science, vol. 110, no. 7, pp. 881-887, 1997.

[14] V. M. Shpacovitch, G. Varga, A. Strey et al., "Agonists of proteinase-activated receptor-2 modulate human neutrophil cytokine secretion, expression of cell adhesion molecules, and migration within 3-D collagen lattices," Journal of Leukocyte Biology, vol. 76, no. 2, pp. 388-398, 2004.

[15] V. Witko-Sarsat, P. Rieu, B. Descamps-Latscha, P. Lesavre, and L. Halbwachs-Mecarelli, "Neutrophils: molecules, functions and pathophysiological aspects," Laboratory Investigation, vol. 80, no. 5, pp. 617-653, 2000.

[16] M. A. Horisberger, "Interferons, Mx genes, and resistance to influenza virus," American Journal of Respiratory and Critical Care Medicine, vol. 152, no. 4, pp. S67-S71, 1995.

[17] F. Flohr, S. Schneider-Schaulies, O. Haller, and G. Kochs, "The central interactive region of human MxA GTPase is involved in GTPase activation and interaction with viral target structures," FEBS Letters, vol. 463, no. 1-2, pp. 24-28, 1999.

[18] V. M. Shpacovitch, S. Seeliger, M. Huber-lang et al., "Agonists of proteinase-activated receptor-2 affect transendothelial 
migration and apoptosis of human neutrophils," Experimental Dermatology, vol. 16, no. 10, pp. 799-806, 2007.

[19] M. Doss, M. R. White, T. Tecle et al., "Interactions of $\alpha-, \beta$-, and $\theta$-defensins with influenza A virus and surfactant protein D," The Journal of Immunology, vol. 182, no. 12, pp. 7878-7887, 2009.

[20] K. Yamamoto, T. Miyoshi-Koshio, Y. Utsuki, S. Mizuno, and K. Suzuki, "Virucidal activity and viral protein modification by myeloperoxidase: a candidate for defense factor of human polymorphonuclear leukocytes against influenza virus infection," Journal of Infectious Diseases, vol. 164, no. 1, pp. 8-14, 1991.

[21] X. Su, E. Camerer, J. R. Hamilton, S. R. Coughlin, and M. A. Matthay, "Protease-activated receptor-2 activation induces acute lung inflammation by neuropeptide-dependent mechanisms," The Journal of Immunology, vol. 175, no. 4, pp. 25982605, 2005.

[22] M. D. Bootman, T. J. Collins, L. Mackenzie, H. Llewelyn Roderick, M. J. Berridge, and C. M. Peppiatt, "2-Aminoethoxydiphenyl borate (2-APB) is a reliable blocker of store-operated $\mathrm{Ca}^{2+}$ entry but an inconsistent inhibitor of $\mathrm{InsP}_{3}$-induced $\mathrm{Ca}^{2+}$ release," FASEB Journal, vol. 16, no. 10, pp. 1145-1150, 2002.

[23] I. C. Allen, M. A. Scull, C. B. Moore et al., "The NLRP3 inflammasome mediates in vivo innate immunity to influenza A virus through recognition of viral RNA," Immunity, vol. 30, no. 4, pp. 556-565, 2009.

[24] J. Bylund, S. Pellme, H. Fu et al., "Cytochalasin B triggers a novel pertussis toxin sensitive pathway in TNF-alpha primed neutrophils," BMC Cell Biology, vol. 5, article 21, 2004.

[25] P. G. Barlow, P. Svoboda, A. Mackellar et al., "Antiviral activity and increased host defense against influenza infection elicited by the human cathelicidin LL-37," PloS ONE, vol. 6, no. 8, Article ID e25333, 2011.

[26] C. Ehrhardt, R. Seyer, E. R. Hrincius, T. Eierhoff, T. Wolff, and S. Ludwig, "Interplay between influenza A virus and the innate immune signaling," Microbes and Infection, vol. 12, no. 1, pp. 8187, 2010.

[27] M. Aebi, J. Fäh, N. Hurt et al., "cDNA structures and regulation of two interferon-induced human Mx proteins," Molecular and Cellular Biology, vol. 9, no. 11, pp. 5062-5072, 1989.

[28] S. Mahalingam, J. Meanger, P. S. Foster, and B. A. Lidbury, "The viral manipulation of the host cellular and immune environments to enhance propagation and survival: a focus on RNA viruses," Journal of Leukocyte Biology, vol. 72, no. 3, pp. 429-439, 2002. 


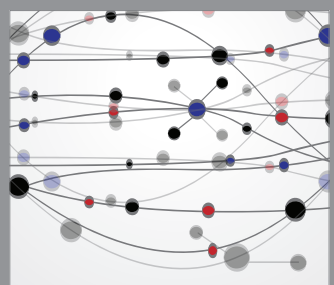

The Scientific World Journal
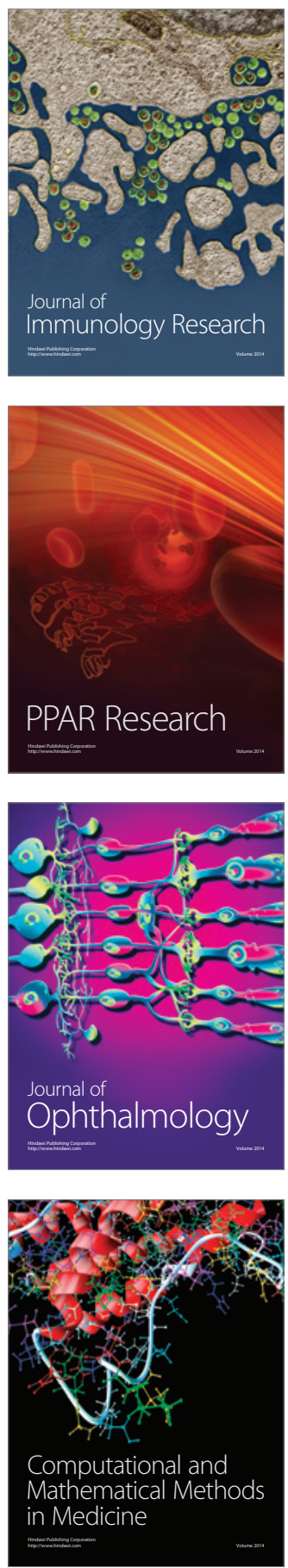

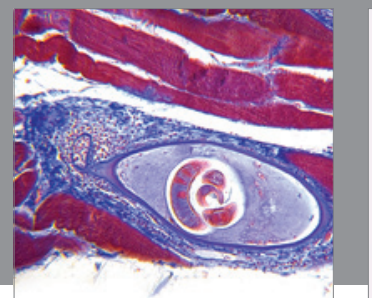

Gastroenterology

Research and Practice
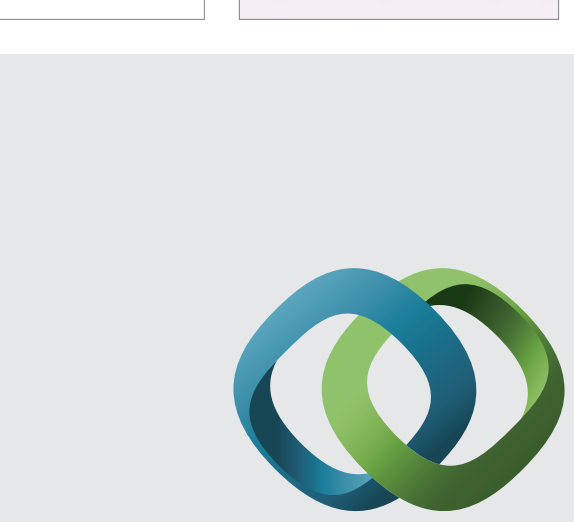

\section{Hindawi}

Submit your manuscripts at

http://www.hindawi.com
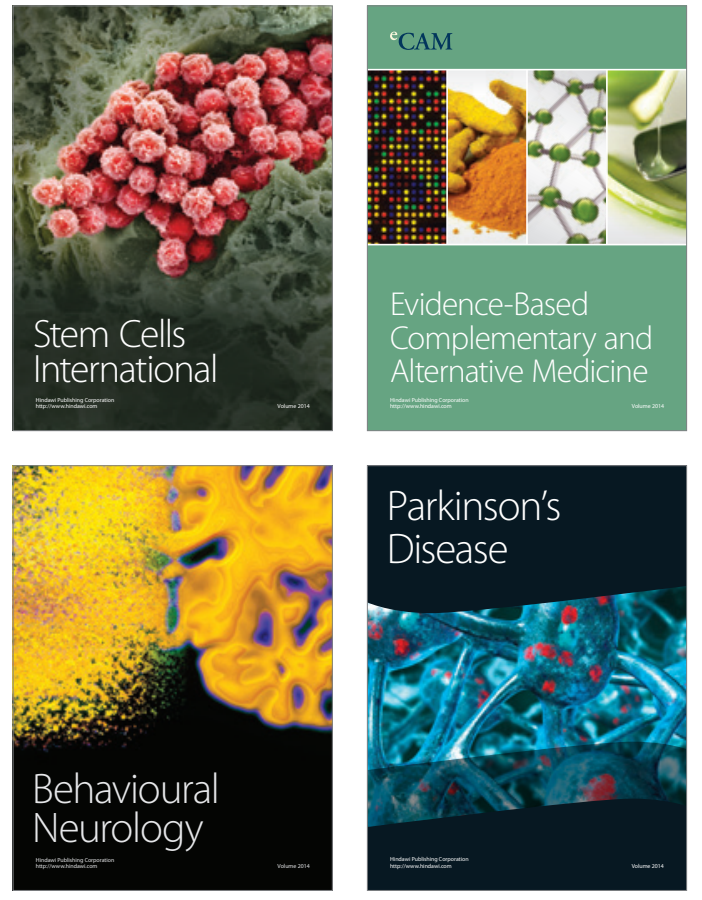
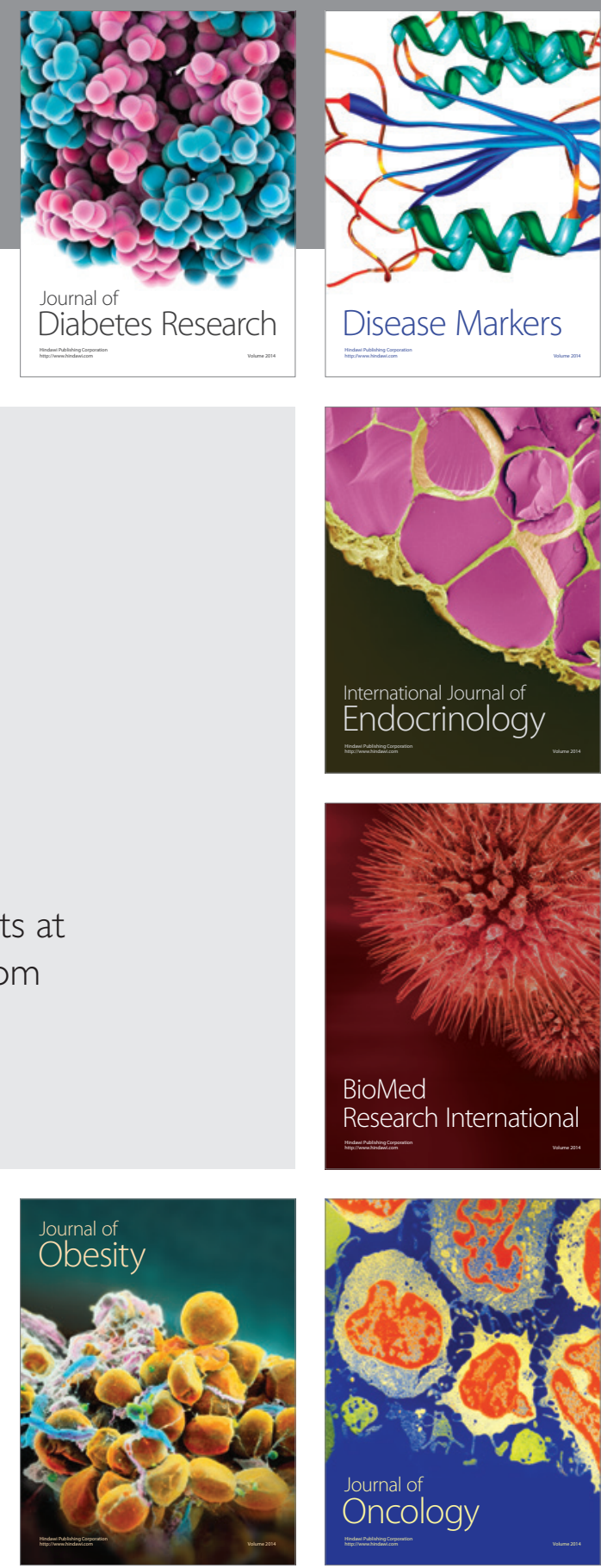

Disease Markers
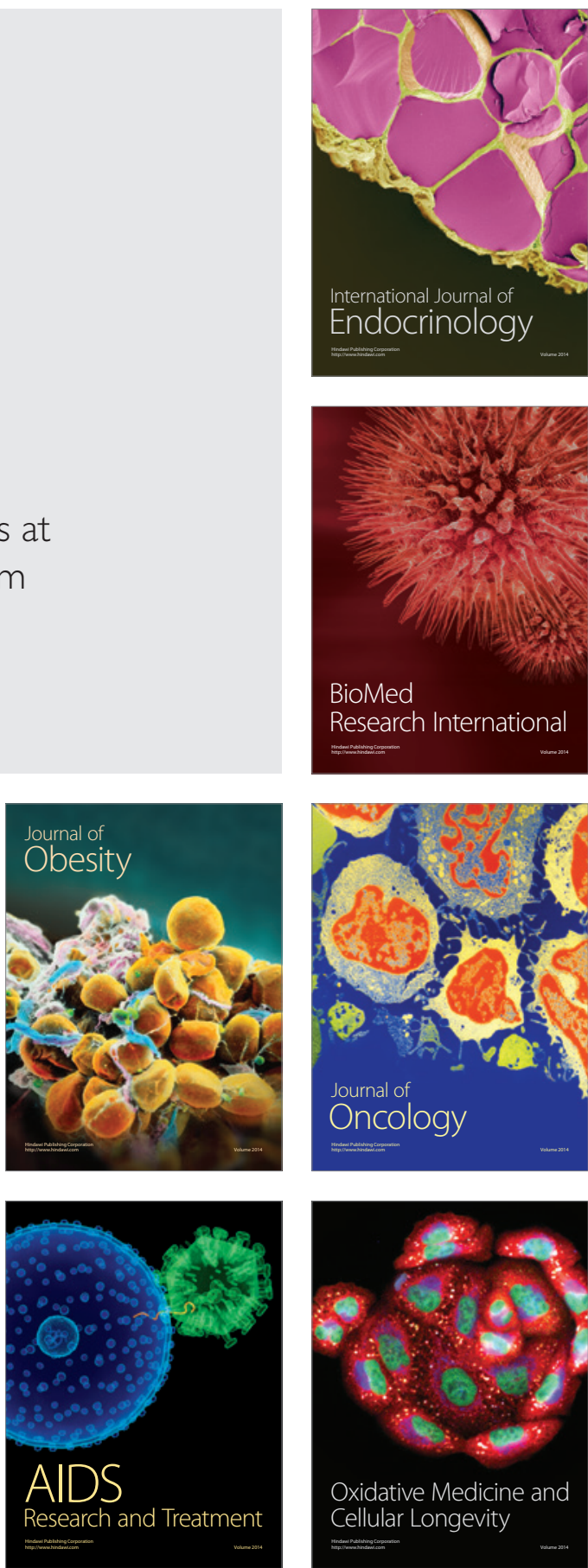